CVIA

REVIEW ARTICLE

pISSN 2508-707X / elSSN 2508-7088 https://doi.org/10.22468/cvia.2018.00094 CVIA 2018;2(4):153-165
Received: April 15, 2018

Revised: May 30, 2018

Accepted: June 21, 2018

Corresponding author

Akira Kurata, MD, PhD

Department of Radiology,

Ehime University Graduate

School of Medicine,

Shitsukawa, Toon 791-0295, Japan

Tel: 81-89-960-5371

Fax: 81-89-960-5375

E-mail: akuratasan2000@gmail.com

\section{Clinical Applications of Three-Dimensional Printing in Cardiovascular Disease}

\author{
Akira Kurata1, Yasushi Koyama², \\ Takashi Shirakawa ${ }^{3,4}$, Toru Miyoshi ${ }^{5}$ \\ 'Department of Radiology, Ehime University Graduate School of Medicine, Toon, Japan \\ 2Sakurabashi Watanabe Hospital, Osaka, Japan \\ ${ }^{3}$ Kansai Rosai Hospital, Amagasaki, Japan \\ ${ }^{4}$ Kinan Hospital, Kinan, Japan \\ ${ }^{5}$ Okayama University Graduate School of Medicine, Dentistry and Pharmaceutical Sciences, \\ Okayama, Japan
}

Cardiovascular three-dimensional (3D) printing models have been focused as an emerging technology. Using 3D volume dataset with the high-quality image obtained from CT, MRI or echocardiography, 3D printing models are produced and can provide tangible spatial perception for cardiovascular anatomy and diseases to conventional two-dimensional diagnostic imaging. Recent studies have shown the expanding feasibility of 3D printing models from procedural planning and simulation for surgical or trans-catheter interventions to training, education and communication for medical professionals and patients, particularly in complex congenital heart disease, structural heart disease, and hybrid cardiovascular surgery. With 3D printing technology and material engineering, 3D printing models can replicate not only the morphology but also the function that allows advanced physiological evaluation, procedural simulation, and a platform to 3D bio-printing. This review summarizes cardiovascular 3D printing model workflow from data acquisition to production and discusses clinical applications of 3D printing models.

Key words 3D printing - Congenital heart defect · Heart valve disease Surgical procedure $\cdot$ Simulation training.

\section{INTRODUCTION}

Three-dimensional (3D) printing technology had been developed in the 1980s. With the recent developments in technologies and materials for industrial 3D models, the decline in price, and the patent-free availability of 3D printing technologies, 3D printing has becoming increasingly popular in various fields.

In medicine, diagnostic imaging plays an important key role for diagnosis, therapeutic planning, and follow-up. CT, MRI, ultrasound (US), and rotation angiography have been used in clinical practice. Most diagnostic imaging technologies involve reconstruction in a Digital Imaging and Communication in Medicine (DICOM) format, which allows effective two-dimen-

(c) This is an Open Access article distributed under the terms of the Creative Commons Attribution Non-Commercial License (https://creativecommons.org/licenses/by$\mathrm{nc} / 4.0$ ) which permits unrestricted non-commercial use, distribution, and reproduction in any medium, provided the original work is properly cited. sional or 3D visualization of the anatomy and of certain diseases. Current post-processing technologies easily covert DICOM images to Stereolithography or Standard Tessellation Language (STL) file formats in a 3D printed model. Clinical applications of 3D printing in medicine have been launched for surgical planning in a wide range of patient-specific implants, such as skeletal structures, dental implants, and cranio-maxillofacial implants [1].

In cardiovascular disease, the 3D printing model is among the latest emerging technologies used in clinical practice and research [2-5]. In this review, we introduce the workflow of 3D printing technologies from data acquisition to the final 3D-printed model and discuss its current clinical applications. We also present several practical uses of 3D printing modeling technologies and discuss future directions of this emerging technology. 

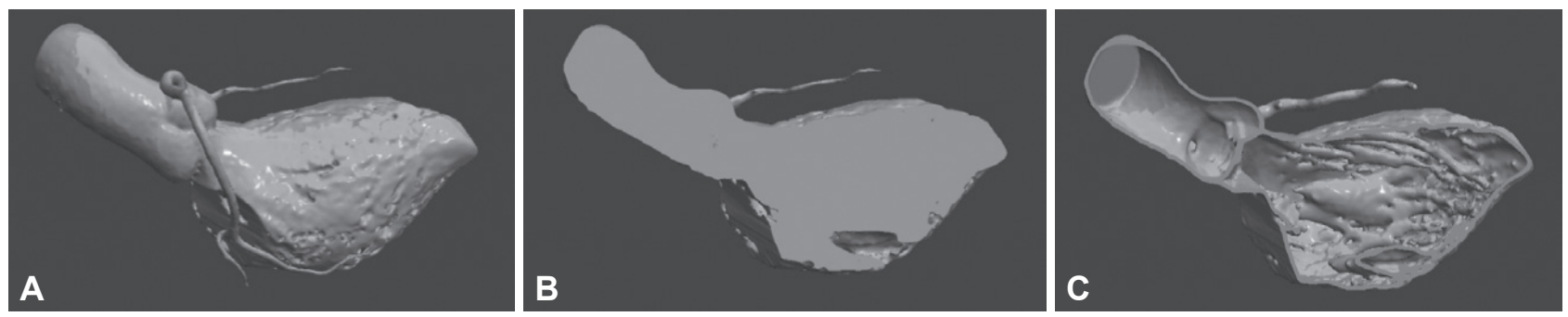

Fig. 1. Graphic representations of the heart. (A) Surface rendering image (overall image). (B) Cross-sectional image of the solid model. (C) Cross-sectional image of the hollow model. The solid model is a simple physical representation of the blood pool image to understand the general three-dimensional anatomy in correlation with the images. Hollow models can be generated from the solid model using computeraided design software or combinations of segmentations.

\section{PRODUCTION OF 3D PRINTING MODEL}

We employed several sequential processes to create a 3D printing model (Fig. 1). From data acquisition to the final 3D-printed model, multiple factors and knowledge of clinical diagnostic imaging deeply relate to 3D printing in terms of correct object recognition for anatomy and pathophysiology. High image quality of 3D volume data and accuracy in each step affect the final model. The concept of 'copying principle', suggesting that it is impossible to produce a product with an accuracy higher than that of the machine used, can be applied not only for the general industry field but also for 3D printing [6]. In this section, we summarize the essential points of the individual processes.

\section{Data acquisition}

The image dataset for 3D printing is required for high image quality with high spatial resolution and without misregistration. CT is one of the most suitable modalities for $3 \mathrm{D}$ printing because it provides the isovolumetric images with high spatial resolution, and it is widely available in clinical practice. MRI has great advantages including no radiation exposure, high temporal resolution, and tissue differentiation capabilities that allow multiple properties to 3D print models. To minimize motion artifacts, electrocardiogram gating and breath-hold (or MRI respiratory gating system) are indispensable for high-quality data acquisition. Some case reports and clinical studies have shown the feasibility of 3D echocardiography and rotational angiography, although these studies do have limitations such as limited acoustic window, temporal resolution, and potential misalignment of the summation data obtained from several heart beats [7-9]. When the data acquisition is performed using CT, optimization of scan parameters, contrast-injection protocols, and conventional diagnostic imaging are improved, which creates the binary images for regions of interest used for 3D printing in the next process of 'segmentation' described below. Sufficient and homogenous contrast enhancement of the cardiac cavities and major vessels is crucial, as is avoidance of extremely high attenuation and inhomogeneous attenuation using a multiplephase contrast injection protocol [10].

\section{Data segmentation}

To obtain the best cardiovascular anatomy of morphological and functional assessment, the volume data of artifact-less cardiac phase with thinner slice thickness is preferable for segmentation. The acquired dataset using the DICOM format is transferred to a free software program (OsiriX MD; Pixmeo, Geneva, Switzerland) or to commercially available software (VirtualPlace Arata, AZE Ltd., Tokyo, Japan; IntelliSpace Portal Version 8.0.1.20640, Philips Healthcare, Cleveland, OH, USA; or $3 \mathrm{D}$ printing v1.2.0, syngo.via Frontier, Siemens Healthcare AG, Forchheim, Germany) in the workstation.

Thresholding and region growing are often used for image segmentation. Thresholding is a simple method that generates binary images based on a threshold (or range) of signal intensity, such as CT attenuation. Region growing iterates examination of neighboring pixels of initial seed points regarding whether the pixel neighbors are classified based on the region. With regard to region growing, effectively using 'vessel mode' and 'general object mode, which are different expansion (erosion) methods of the volume of interest based on purpose, is important. Because segmentation is affected by multiple influencing factors of the original image (attenuation, image noise, texture, size, and shape of the interest), generating binary images using thresholding and region growing combined with other post-processing mathematical morphologies such as 'dilation' and 'erosion' while referring to the original CT images will be better. Although the automatic software for cardiac CT can be used for standard cardiovascular anatomy, individual CT attenuation-based image segmentation for binary images works effectively for cardiac valves [11].

In cardiovascular 3D printing models, solid and hollow models are often applied. The solid model in the blood pool image is relatively easily segmented when contrast enhancement is uniformly sufficient. The hollow model is generated using the above-mentioned segmentation methods combined with summation and subtraction. Representative images and general features of the solid and hollow models for cardiovascular disease are shown in Fig. 1 and Table 1.

The requirements for effective segmentation are 1) knowledge 
Table 1. Comparison between solid and hollow models

\begin{tabular}{|c|c|c|}
\hline Method & Solid model & Hollow model \\
\hline Segmentation & Relatively easy & $\begin{array}{l}\text { Difficulty depends on the structure } \\
\text { of the model }\end{array}$ \\
\hline $\begin{array}{l}\text { Preprocessing of 3D STL models } \\
\text { (data correction and design) }\end{array}$ & Easy & $\begin{array}{l}\text { Required for processing } \\
\text { (design for assembly or closed space) }\end{array}$ \\
\hline Hardness & Generally solid & Depends on thickness and structure \\
\hline Production time for 3D printing models & Long & Relatively short \\
\hline Cost for materials & Large (relatively expensive) & Small (relatively reasonable) \\
\hline Merits and limitations & $\begin{array}{l}\text { General understanding of the } 3 \mathrm{D} \text { anatomy } \\
\text { Less information for depth or internal structures }\end{array}$ & $\begin{array}{l}\text { Much information for depth and internal } \\
\text { structures } \\
\text { Less accuracy for size and volume }\end{array}$ \\
\hline $\begin{array}{l}\text { Clinical applications for cardiovascular } \\
\text { disease }\end{array}$ & $\begin{array}{l}\text { Blood pool image (vessels, heart), myocardium, } \\
\text { calcification (vessels, valves), atherosclerotic plaque }\end{array}$ & $\begin{array}{l}\text { Vessels, coronary artery, cardiac chambers, } \\
\text { and models for simulation and training }\end{array}$ \\
\hline
\end{tabular}

3D: three-dimensional, STL: Stereolithography or Standard Tessellation Language

Table 2. Summary of 3D printers used

\begin{tabular}{|c|c|c|c|c|c|c|}
\hline Method & Model & Company & $\begin{array}{c}\text { Price for } \\
\text { printer } \\
(\$)\end{array}$ & $\begin{array}{l}\text { Layer } \\
\text { pitch } \\
(\mu \mathrm{m})\end{array}$ & $\begin{array}{l}\text { Maximum object } \\
\text { dimensions }(\mathrm{mm})\end{array}$ & Materials used \\
\hline FDM* $^{*}$ & UP Plus2 & Tiertime Tech. (Milpitas, CA, USA) & 1400 & $150-400$ & $140 \times 140 \times 130$ & ABS, PLA (resin) \\
\hline $\mathrm{FDM}^{*}$ & SCOOVO X9 & Abee Corp. (Yokohama, Kanagawa, Japan) & 2000 & 50 & $230 \times 200 \times 170$ & ABS, PLA (resin) \\
\hline SLA & Form 1+ & Formlabs (Somerville, MA, USA) & 4600 & $25-100$ & $145 \times 145 \times 175$ & Resin \\
\hline SLS* & EOSINT P7 & EOS GmbH (Krailling/ Munich, Germany) & $>92000$ & $60-180$ & $700 \times 380 \times 580$ & Nylon \\
\hline CJP* & ProJet660 Pro & 3D Systems (Rock Hill, SC, USA) & 84000 & 100 & $254 \times 381 \times 203$ & Gypsum powder \\
\hline Ink jet* & Projet5500X & 3D Systems & $>190000$ & 29,32 & $518 \times 381 \times 295$ & Acrylic resin \\
\hline Ink jet & Objet260 Connex 3 & Stratasys (Eden Prairie, MN, USA) & $>190000$ & 16,30 & $255 \times 252 \times 200$ & Multi-material printing \\
\hline Ink jet* & Objet350 Connex 3 & Stratasys & $>280000$ & 16,30 & $342 \times 342 \times 200$ & Multi-material printing \\
\hline
\end{tabular}

The table shows some examples that authors have used for generating 3D printing model in cardiovascular disease. *3D printers used in outsourcing service. Adapted from Koyama and Suzuki, with permission of CHUGAIIGAKU Co., Ltd. [6]. ABS: acrylonitrile butadiene styrene, CJP: color-jet printing, FDM: fused deposition modeling, ink jet: material-jet printing (MJP), PLA: polylactic acid, SLA: stereo-lithography apparatus, SLS: selective laser sintering, 3D: three-dimensional

of cardiovascular anatomy and pathophysiology (disease condition), 2) range of 3D printing, and 3) awareness of divisional design for clinical use. Although the latter two items are unfamiliar at the onset, they are essential for the following the process of production and clinical applications of 3D printing models.

\section{Conversion of file format for 3D printing}

The 3D volume-rendered DICOM image files are converted to the applicable file format for computer-aided design (CAD) and $3 \mathrm{D}$ printing. STL is a standard file format used for $3 \mathrm{D}$ printing and is supported by most $3 \mathrm{D}$ printer software. It only describes the surface geometry of a 3D object without any other information. Some other file formats (OBJ, 3MF, or AMF) can encode not only surface geometry but also color, texture, and other characteristics; thus, these might also be used as other standard file formats for 3D printing. Knowing in advance the file format applicable for the institutional strategies of $3 \mathrm{D}$ printing is recommended.

\section{Preprocessing of 3D STL models}

Converted STL file data often contain unnecessary noise, incomplete objects, and excessive data capacity. Clean-up, correction, verification, and smoothing of STL file data are required using available CAD software: e.g., MeshLab (Italian National Research Council, Italy), Meshmixer (Autodesk Inc., San Rafael, CA, USA). 'Volume reduction' by limiting the model size can save costs for production time and materials.

\section{Production of 3D printing models}

In cardiovascular disease, several 3D printing technologies have been used such as fused deposition modeling, stereo-lithography apparatus, selective laser sintering, color-jet printing, and material-jet printing. These technologies are based on the dedicated technology, such as material extrusion, vat photopolymerization, powder bed fusion, material jetting, difference in available materials, accuracy, cost, and individual features [6, 12,13 ]. Table 2 shows a summary of 3D printers that we used in clinical practice and research [6]. As 3D printing technolo- 
gies and the available materials that regulate the property of the final 3D printed models are closely related, building institutional workflow and using both in-house and out-sourced 3D laboratories wisely, depending on purpose and cost-effectiveness, will become more effective (Table 3 ).

\section{Post-processing of 3D printed models}

For most 3D printing technologies, production includes support materials (Fig. 2). Following the manufacturer's specifications for proper material post-processing and cleaning are recommended. However, post-processing may become a ratelimiting factor and should be considered as an influencing factor prior to all production steps, which will avoid the difficulty in cleaning up support materials in complex or closed spaces.

\section{CLINICAL APPLICATIONS}

Cardiovascular 3D printing models can be generated for various applications in clinical practice and research (Table 4). They are not always required for standard diagnosis of cardiovascular diseases or simple cardiovascular surgery and intervention. Many children with congenital heart disease (CHD) have become adults, and trans-catheter therapy became an option for structural heart disease (SHD). Additionally, 3D printing models can further provide a physical, spatial perception for cardio- vascular anatomy, disease morphology, which can be used for patient-tailored management, including procedural planning among the heart team (radiologists, pediatricians, cardiologists, and cardiac surgeons). Moreover, 3D printing models are helpful for medical professionals, patients, and their family members to better understand procedures and are expected to be used for medical advancements such as medical education, training, patient-specific therapies, and medical devices.

\section{Myocardial disease}

\section{Hypertrophic cardiomyopathy}

Hypertrophic cardiomyopathy (HCM) is a genetic myocardial disease characterized by regional or diffuse left ventricular hypertrophy [14]. Translating the understanding of pathophysiology to a physical procedure during surgical intervention for HCM is sometimes difficult. 3D printing models can replicate the accurate anatomy of hemodynamically significant hypertrophied myocardium and combined anomalies of the papillary muscle and allow for successful surgical septal myectomy without complications by selecting suitable pathophysiologyoriented procedures [15]. The 3D printed models can also provide detailed spatial information not only in the left ventricular outflow tract obstruction due to HCM but also for aortic stenosis (AS) using a systolic image dataset (Fig. 3).

Table 3. Comparison of in-house and out-sourcing 3D printing

\begin{tabular}{lll}
\hline & \multicolumn{1}{c}{ In-house 3D printing } & \multicolumn{1}{c}{ Out-sourcing 3D printing } \\
\hline Initial cost & \multicolumn{1}{c}{ All-inclusive ideal requirements } & \multicolumn{1}{c}{ Optional selection for material and expert technique } \\
Operating expenses & Migh (3D printers and materials) & None \\
Time cost & Time-efficient & Individual fee per client \\
Advantages & Close communication of 3D lab and physicians & Relatively time-consuming \\
& Available for customized model & Usage of expert technique for segmentation and materials \\
Disadvantages & Needs learning period & \\
& Limited hardware and material options & Less clinical and medical information \\
\hline
\end{tabular}

3D: three-dimensional

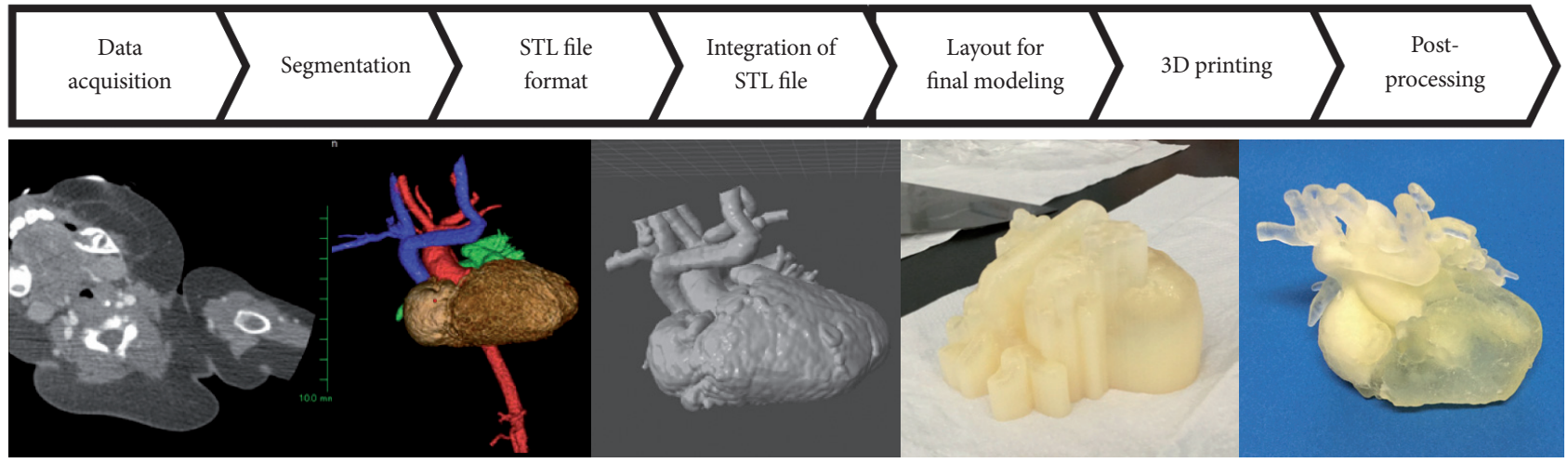

Fig. 2. Work flow of 3D printing. 3D: three-dimensional, STL: Stereolithography or Standard Tessellation Language. 


\section{Double-chambered right ventricle}

Double-chambered right ventricle (DCRV) is a rare heart defect wherein an anomalous muscle bundle separates part of the right ventricular outflow tract (RVOT) from the right ventricle
[16]. The 3D anatomy of DCRV is complex, and changes in the cardiac cycle necessitate detailed patient-tailored surgical planning [17]. Separable 3D printing models in systole and diastole allow overall and regional surgical planning, providing effec-

Table 4. Summary of 3D printing models for cardiovascular diseases

\begin{tabular}{|c|c|c|c|c|}
\hline First author (Ref. no) & Diagnosis & Modality & Printing methodology & Findings/Key points \\
\hline \multicolumn{5}{|l|}{ Myocardial disease } \\
\hline Yang et al. [15] & $\mathrm{HCM}$ & CT & Hollow model/Ink jet/rubber-like & Guide model for surgical myectomy \\
\hline Shirakawa et al. [17] & DCRV & CT & Hollow model/FDM/ABS & Guide model for surgical myectomy \\
\hline \multicolumn{5}{|l|}{ Cardiac valves } \\
\hline Fujita et al. [22] & AS & CT & Hollow model/Ink jet/rubber-like & Assessment of aortic valve calcification \\
\hline Ripley et al. [23] & AS, post-TAVI & $\mathrm{CT}$ & Hollow model/FDM/flexible resin & $\begin{array}{l}\text { Experiment designed to predict } \\
\text { paravalvular leaks }\end{array}$ \\
\hline Witschey et al. [9] & Normal, diseased MV & US & Solid model/FDM/plastic & $\begin{array}{l}\text { Physical models at end systole and end } \\
\text { diastole }\end{array}$ \\
\hline Shirakawa et al. [11] & MVP & $\mathrm{CT}$ & Hollow model/various materials & $\mathrm{CT}$ attenuation-based segmentation of $\mathrm{MV}$ \\
\hline Dankowski et al. [29] & $\mathrm{MR}$ & CT & Hollow model/SLA/resin & Planning for trans-catheter interventions \\
\hline \multicolumn{5}{|l|}{ Congenital heart disease } \\
\hline Shiraishi et al. [34] & Complex CHDs & CT & Hollow model/SLS/plastic, urethane & $\begin{array}{l}\text { Simulation until to cut and suture } \\
\text { the } 3 \mathrm{D} \text { model }\end{array}$ \\
\hline Mottl-Link et al. [37] & Complex CHDs & MRI & Solid, hollow models/CJP/Gypsum & Respiratory-gated data acquisition \\
\hline Noecker et al. [40] & Complex CHDs & $\mathrm{CT}$ & Hollow model/CJP/flexible silicon & $\begin{array}{l}\text { Silicon-coated powder mold removable } \\
\text { in a water bath }\end{array}$ \\
\hline \multicolumn{5}{|l|}{ Aortic disease } \\
\hline Schmauss et al. [48] & Aortic aneurysm & $\mathrm{CT}$ & Sold model/CJP/coated with resin & $\begin{array}{l}\text { Multi-physic model with solid material } \\
\text { and elastic resin }\end{array}$ \\
\hline Valverde et al. [49] & $\mathrm{CoA}$ & MRI & Solid and hollow models/PLA & Planning for endovascular stenting \\
\hline Shijo et al. [50] & $\begin{array}{l}\text { Aortic aneurysm } \\
\text { with CoA }\end{array}$ & CT & Hollow model/ink jet/rubber-like & $\begin{array}{l}\text { Surgical simulation for endovascular } \\
\text { stenting }\end{array}$ \\
\hline \multicolumn{5}{|l|}{ Cardiac tumor } \\
\hline Jacobs et al. [55] & Cardiac tumor & $\mathrm{CT}$ & Hollow model/CJP/gypsum & $\begin{array}{l}\text { Pre-operative planning, LV restoration } \\
\text { for LV aneurysm }\end{array}$ \\
\hline \multicolumn{5}{|l|}{ Education and training } \\
\hline Biglino et al. [56] & $\mathrm{CHD}$ & MRI & Solid model/SLS/rigid material & $\begin{array}{l}\text { Education, medical consulting for patients } \\
\text { and family }\end{array}$ \\
\hline Costello et al. [58] & VSD & MRI & Hollow model/ink jet/rubber-like & Education for trainees \\
\hline Yoo et al. [61] & DORV & $\mathrm{CT}$ & Hollow model/ink jet/rubber-like & Education and hands-on surgical training \\
\hline \multicolumn{5}{|l|}{ Future directions } \\
\hline Kolli et al. [62] & Coronary artery & CT & Hollow model/ink jet/rigid material & $\begin{array}{l}\text { 3D model simulation on invasive } \\
\text { FFR measurement }\end{array}$ \\
\hline Maragiannis et al. [63] & AS & CT & Hollow model/ink jet/rubber-like & $\begin{array}{l}\text { Multiphysics model, anatomic and } \\
\text { functional properties }\end{array}$ \\
\hline Biglino et al. [65] & Vessel & MRI & Hollow model/ink jet/rubber-like & $\begin{array}{l}\text { In-vitro compliance test of arterial } \\
\text { 3D model }\end{array}$ \\
\hline Shirakawa et al. [67] & AS & CT & Hollow model/ink jet/rubber-like & $\begin{array}{l}\text { Multiphysics model with crushable } \\
\text { calcification }\end{array}$ \\
\hline
\end{tabular}

AS: aortic stenosis, CHD: congenital heart disease, CJP: colour jet printing, DCRV: dual-chambered right ventricle, FDM: fused deposition modelling, ABS: acrylonitrile butadiene styrene, HCM: hypertrophic cardiomyopathy, ink jet: material-jet printing, MV: mitral valve, MVP: mitral valve prolapse, MR: mitral regurgitation, US: ultrasound, SLA: stereo-lithography apparatus, TAVI: trans-catheter aortic valve intervention, CoA: coarctation of aorta, PLA: polylactic acid/polylactide, VSD: ventricular septal defect, DORV: double-outlet right ventricle, FFR: fractional flow reserve, 3D: three-dimensional 

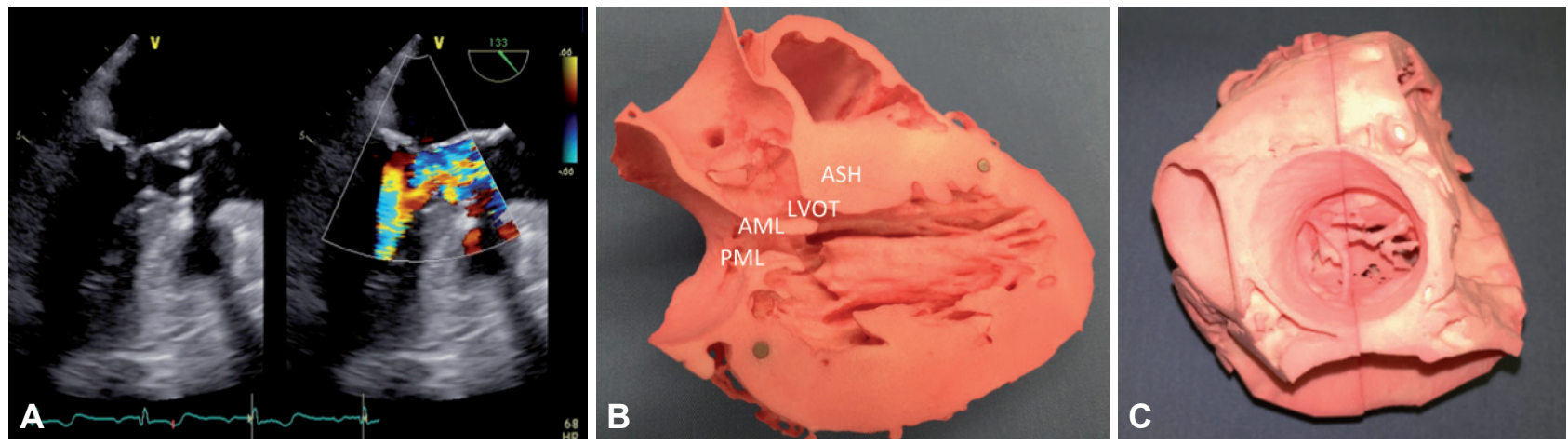

Fig. 3. A 77-year-old woman with comorbidity of HCM and AS. (A) Transesophageal echocardiography shows the left ventricular outflow obstruction by HCM and thickened aortic valve leaflet by AS. (B and C) The 3D printing model replicates the 3D anatomy of the LVOT obstruction with a long-axis sectional model and the surgical view from the aorta with an assembled model. She underwent surgical septal myectomy and aortic valve replacement. Adapted from Koyama and Suzuki, with permission of CHUGAllGAKU Co., Ltd. [6]. HCM: hypertrophic cardiomyopathy, AS: aortic stenosis, 3D: three-dimensional, LVOT: left ventricular outflow tract, ASH: asymmetrical septal hypertrophy, AML: anterior mitral leaflet, PML: posterior mitral leaflet.
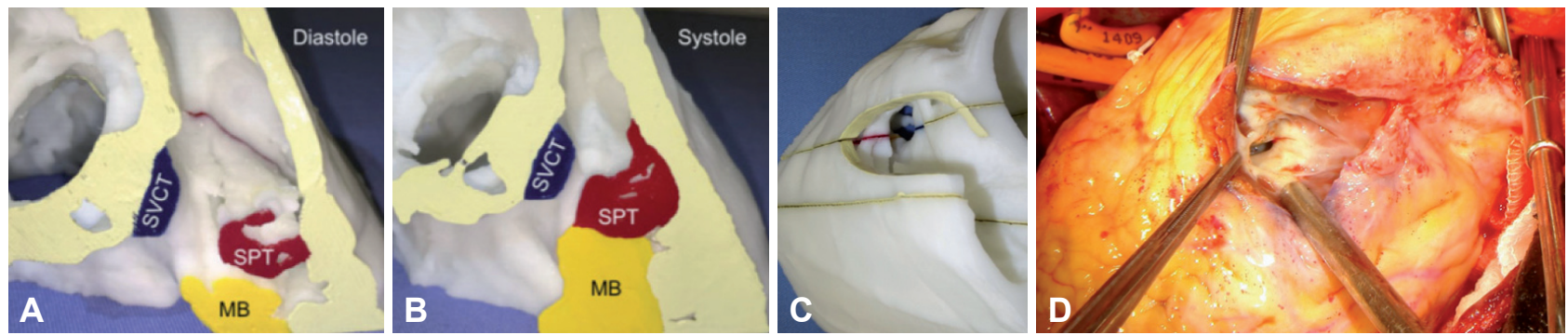

Fig. 4. A 67-year-old woman with DCRV. (A and B) 3D printing models in diastole and systole can identify the 3D anatomical changes of the RVOT obstruction due to the DCRV. The assembled 3D printed model (C) simulates the surgical view through an incision of the pulmonary infundibulum as well as surgical exploration (D). The obstructive bundle was carefully resected until the stenosis was sufficiently reduced. Adapted from Koyama and Suzuki, with permission of CHUGAIIGAKU Co., Ltd. [6] and Shirakawa et al. Interact Cardiovasc Thorac Surg 2016;22:688-690, with permission of Oxford University Press [17]. 3D: three-dimensional, RVOT: right ventricular outflow tract, DCRV: double-chambered right ventricle, SVCT: supraventricular crest, SPT: septoparietal trabecula, MB: moderator band.

tive surgical views (Fig. 4) [13].

\section{Cardiac valves}

\section{Aortic valve}

Surgical and trans-catheter interventions are selected based on the patients' status. In recent years, trans-catheter aortic valve intervention (TAVI) has been rapidly developed and implemented in clinical practice [18-20]. Conventional CT and echocardiography diagnostic imaging provide the indications and intra- and post-procedural assessments for the procedure [21]. In procedural planning, 3D printing models can help attain more insightful spatial information [22-24]. Moreover, multiphysics models predict potential complications in complex cases by mimicking the tissue properties (Fig. 5). In addition to objectivity and reproducibility, selection of cardiac phase is crucial for the assessment and production of 3D printed models $[8,25]$. Recent studies reported the advanced feasibility of 3D printed models for TAVI procedures, such as ex vivo studies of valve-in-valve procedures [26].

\section{Mitral valves}

The mitral valve and its related surrounding structures have a mutual functional anatomy and thinner structures that, in normal cases, are difficult to be replicated with $3 \mathrm{D}$ printing models. Some studies reported that the dedicated segmentation of 3D transesophageal echocardiography enables the production of $3 \mathrm{D}$ physical models in normal and diseased mitral valves and annuli $[9,27]$. A recent study reported an objective segmentation of the mitral valve based on CT attenuation (Fig. 6) $[10,14]$. Trans-catheter interventions in the mitral valve have also been rapidly developed and are now available in clinical practice. 3D printed models may aid in the planning and simulation of a MitraClip (Abbott Vascular, Menlo Park, CA, USA) procedure [28-30].

\section{Pulmonary valves}

Pulmonary valve disease is rare among adults but is commonly observed in children, such as those with repaired CHD or undetected congenital pulmonary disease [21]. In addition to the growth of patients (children), trans-catheter valve implantations are not usually recommended. However, 3D printed models 

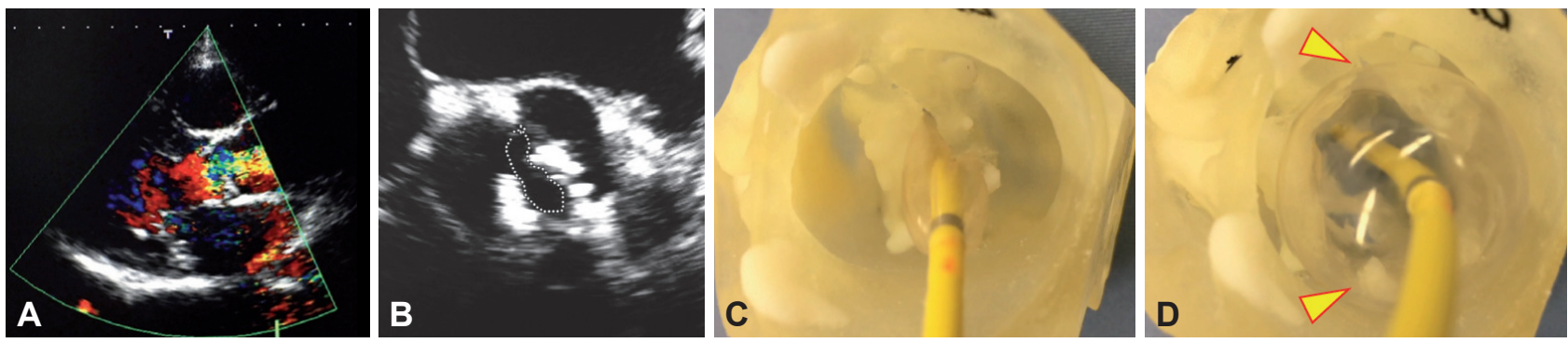

Fig. 5. A 78-year-old woman with AS (bicuspid valve). Echocardiography (A and B) shows severe AS due to bicuspid aortic valve. Multiphysics three-dimensional printing model ( $C$ and $D$ ) was generated with elastic material (antique white) and hard material (white) and used for the simulation of balloon compliance testing before trans-catheter aortic valve intervention, and indicated the heterogeneity of balloon injury to the non-calcified leaflet (yellow arrows). Adapted from Koyama and Suzuki, with permission of CHUGAllGAKU Co., Ltd. [6]. AS: aortic stenosis.
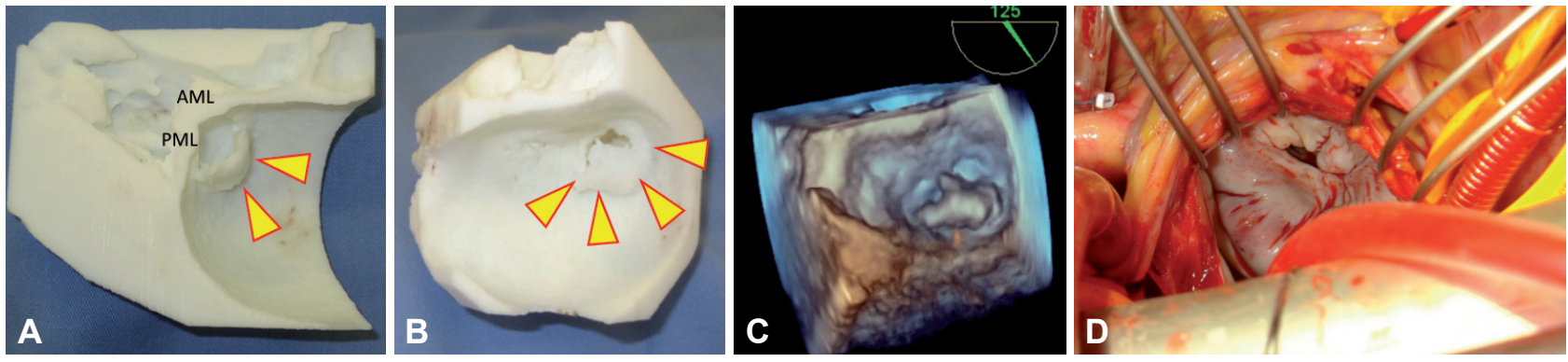

Fig. 6. A 75-year-old woman with mitral regurgitation. (A and B) A solid 3D printing model in systole replicates the prolapse of mitral posterior scallop (P2-P3, yellow arrows). (C) 3D trans-oesophageal echocardiography shows the morphology and function of mitral valve regurgitation by the prolapse. (D) Surgical exploration revealed the location of the prolapse. Surgical repair (partial resection and annuloplasty) was successfully performed without complication. Adapted from Koyama and Suzuki, with permission of CHUGAlIGAKU Co., Ltd. [6]. 3D: three-dimensional, AML: anterior mitral leaflet, PML: posterior mitral leaflet.
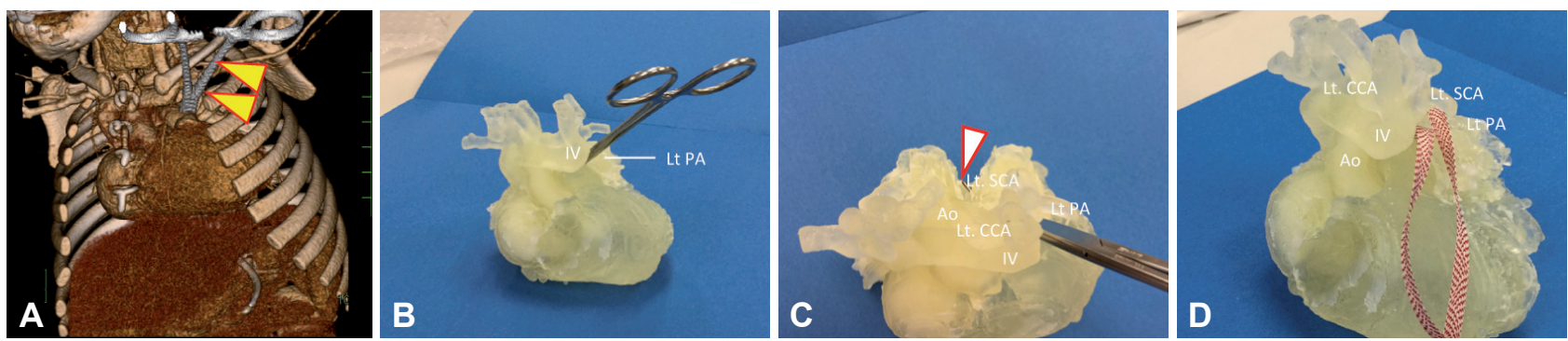

Fig. 7. A 3-year-old girl with complex congenital heart disease. A child presented with a history of tetralogy of Fallot, aortopulmonary window, and several-stage surgeries. A cardiac CT scan was performed in the next staged surgery for residual PA stenosis. (A) CT/CT fusion image with patient's heart and forceps shows virtual surgical exploration to pass the forceps (yellow arrows) over the left PA stenosis (Lt. PA). (B and C) The life-sized 3D printing model replicated the tangible 3D anatomy and allowed physical simulation of surgical procedures. Real forceps (white arrow) could be inserted over the left PA stenosis hidden with IV with minimal deformation of the 3D printed model along the accessible pathway as well as the virtual simulation. (D) The left PA stenosis was marked with surgical vessel tape. PA: pulmonary artery, IV: innominate vein, 3D: three-dimensional, Ao: aorta, SCA: subclavian artery, CCA: common carotid artery. Adapted from Kurata et al. J Cardiovasc Comput Tomogr 2016;10:s7, with permission of Elsevier Inc. [35]

can help assess 3D detailed information of the pulmonary valve and the RVOT before and after trans-catheter pulmonary valve intervention [31].

\section{CHD}

$\mathrm{CHD}$ is one of main topics for the 3D printing model, because of the wide spectrum and various sizes of cardiovascular anatomy and comorbidity. Echocardiography is the first-line imaging modality for the assessment of its anatomy and function, but it is often hampered by a limited acoustic view. Some researchers showed the feasibility of echocardiography for 3D modeling [32]. Other researchers have shown the robustness and high spatial resolution of 3D volume data obtained from CT and MR for 3D printing model of the cardiovascular system [33-37]. The 3D printing provides aid not only for accurate advanced procedural planning with a life-size model [35] (Fig. 7) but also for accurate expanded replicas by multiplying the STL file data [36]. It will be helpful for medical professionals, patients (children), and their family members to understand congenital anomalies, which will be helpful in obtaining informed consent. 
Atrial and ventricular septal defects, patent ductus arteriosus

Ventricular septal defect, atrial septal defect (ASD), and patent ductus arteriosus are among the most common CHDs worldwide and are commonly observed in childhood [38]. They are diagnosed as either isolated or comorbidity in combined with complex CHDs and are managed by surgical repair or transcatheter closure based on the size and the net flow of the blood (shunt) through the defect. 3D printing models are not always required for simple shunt anomalies but can aid in the better understanding of 3D anatomy. Unroofed coronary sinus (CS) is a rare congenital anomaly leading to partial or complete absence of the common wall between the CS and the left atrium; it is hemodynamically classified as a rare type of ASD. In our experience, a 3D printing model is useful for the accurate diagnosis of unroofed CS (Fig. 8).

\section{Complex and severe CHD}

From neonatal screening to medical and surgical management in childhood and adolescence, precise and appropriate diagnosis is essential. Although transthoracic echocardiography is an established non-invasive modality to assess the anatomy and function, more objective and physical 3D information is needed for trans-catheter or surgical intervention for complex and severe CHDs. Some studies have shown clinical applications of
$3 \mathrm{D}$ printed models using various $3 \mathrm{D}$ modalities such echocardiography [32], CT [33-36,39,40], MR [37], and rotational angiography [31]. The 3D printed models are effective for improving the spatial perception of complex congenital abnormalities (Fig. 9).

Although complex CHDs have been managed by pediatricians or in dedicated heart centres, the number of patients with adult CHD has increased because of advanced diagnosis and management, making patient-tailored and precision medicine even more crucial.

\section{Structural heart diseases}

SHDs refer to 'non-coronary cardiovascular disease' that can be treated by trans-catheter interventions; they range from pediatric and adult CHD to acquired heart valvular disease [8,9,1931] and other cardiovascular diseases. For less-invasive non-openheart interventions, precise 3D anatomy is crucial for from diagnosis, to procedural planning and simulation of trans-catheter intervention (Fig. 10) [41-43].

\section{Aortic disease}

For complex cases with severe aortic disease (dissection and aneurysm), thoracic endovascular aortic repair (TEVAR) is a less-invasive option to reduce complications [44-46]. Hybrid
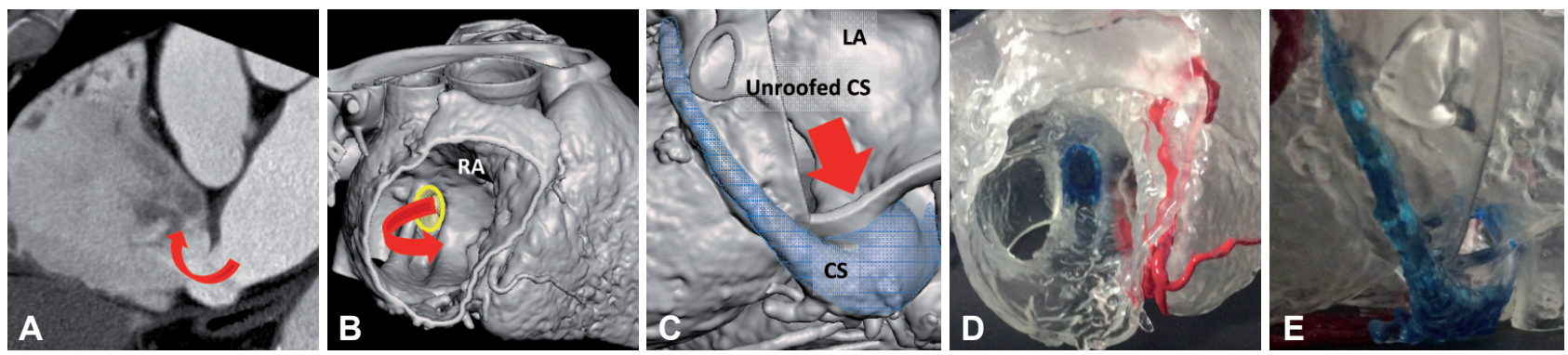

Fig. 8. A 70-year-old man with unroofed CS. CT imaging of the LA from an adult man (A) shows the connection from the LA to the RA via unroofed CS (red arrows) diagnosed with atrial septal defect-associated congenital malformation. Surface rendering images (B and C) visualize the $3 \mathrm{D}$ anatomy for the relationship between the anatomy and connecting structures. The 3D printed model (D and $E)$ shows the tangible anatomy, which confirmed from the views of extra- and intra-cardiac chamber views. LA: left atrium, RA: right atrium, CS: coronary sinus, 3D: three-dimensional.
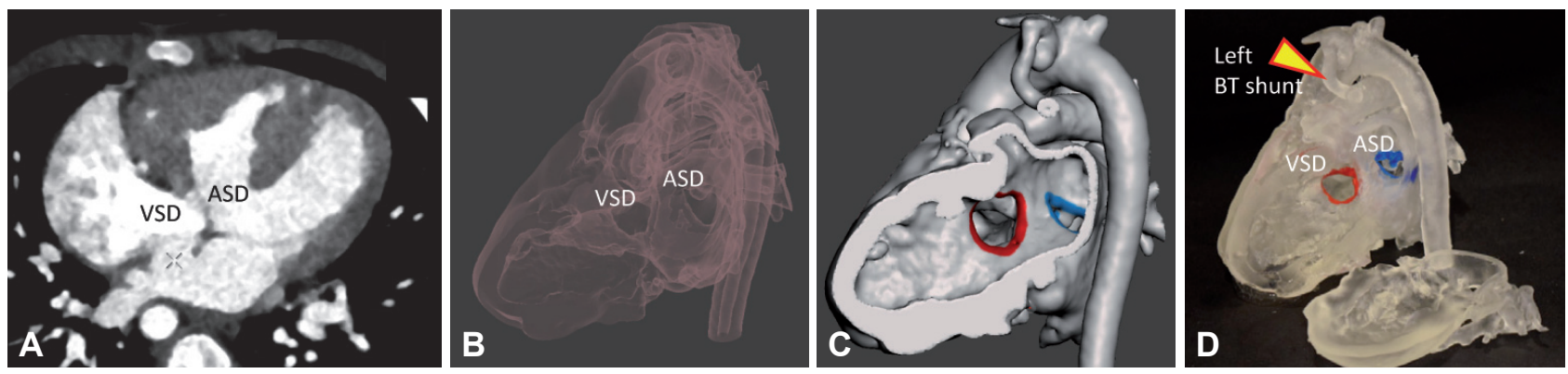

Fig. 9. A 9-month-old boy with trans-position of great arteries type 3. CT axial imaging of a young child shows (A) ASD and VSD. Hollow models of Stereolithography or Standard Tessellation Language file format images show the entire cardiovascular anatomy and anomaly with transparent image (B) and ASD (red) VSD (blue) with cross-sectional surface rendering image (C). A life-size three-dimensional printed model (D) replicated cardiovascular anatomy and anomalies. Adapted from Koyama and Suzuki, with permission of CHUGAIIGAKU Co., Ltd. [6]. ASD: atrial septal defect, VSD: ventricular septal defect, BT-shunt: Blalock-Taussig shunt. 
TEVAR with supra-aortic debranching is the most popular current method of minimally invasive arch reconstruction, particularly in high-risk patients [47]. Some researchers reported the feasibility of 3D printed models for surgical and trans-catheter interventions [48-50]. In our experience, 3D print modeling was helpful as a multi-purpose interactive tool from procedur-
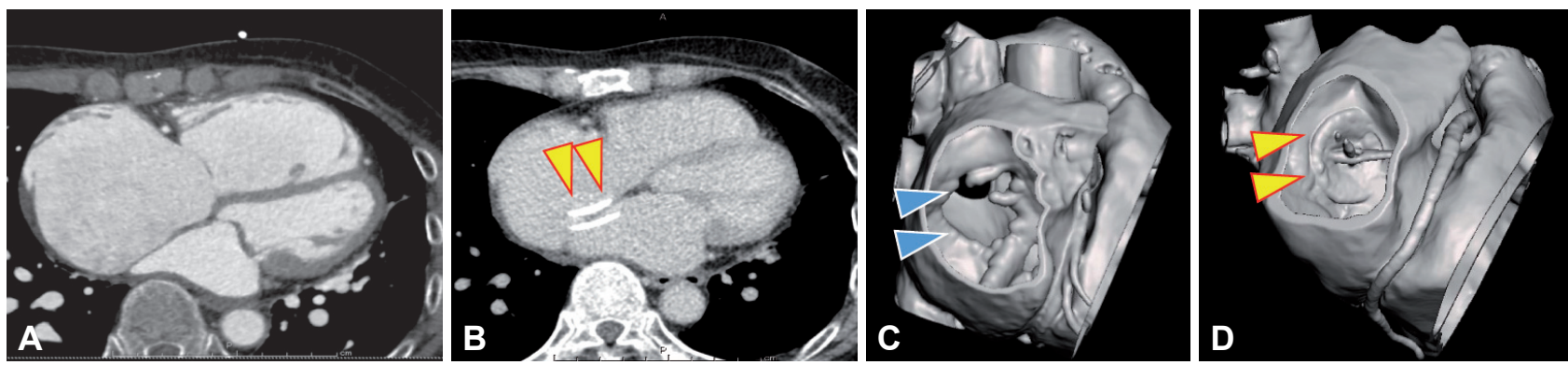

Fig. 10. A 75-year-old woman with ASD. Cardiac CT (A and B) of an elderly woman shows reduced right heart overload due to ASD (blue arrows) before and after trans-catheter ASD closure device deployment (yellow arrows). Surface rendering images by Stereolithography or Standard Tessellation Language file format (C and D) determined that the ASD was covered with the closure device. ASD: atrial septal defect.
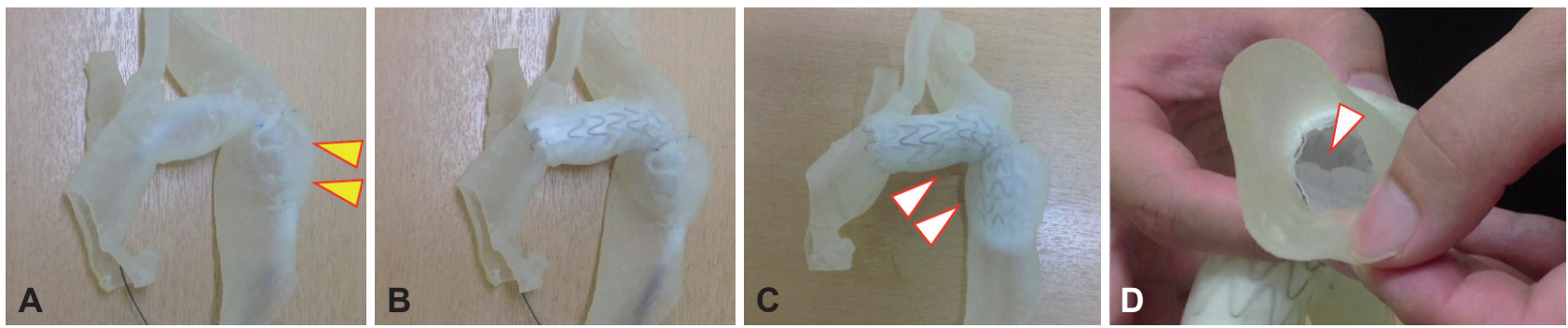

Fig. 11. A 70-year-old woman with aortic aneurysm. An elderly woman underwent the first-stage surgery for aortic valve replacement, ascending aortic repair, and supra-aortic rerouting bypass. A rubber-like 3D printing model (A) replicated the 3D morphology of the aortic aneurysm (yellow arrows) after the first-stage surgery. Procedural simulation (B) was attempted before graft stenting through the TEVAR. Physical TEVAR simulation (C) shows a patent endo-graft lumen without signs of infolding ( $D$, white arrows). Adapted from Shijo et al. Eur J Cardiothorac Surg 2018;54:593-595, with permission of Oxford University Press [50]. TEVAR: thoracic endovascular aortic repair, 3D: three-dimensional.
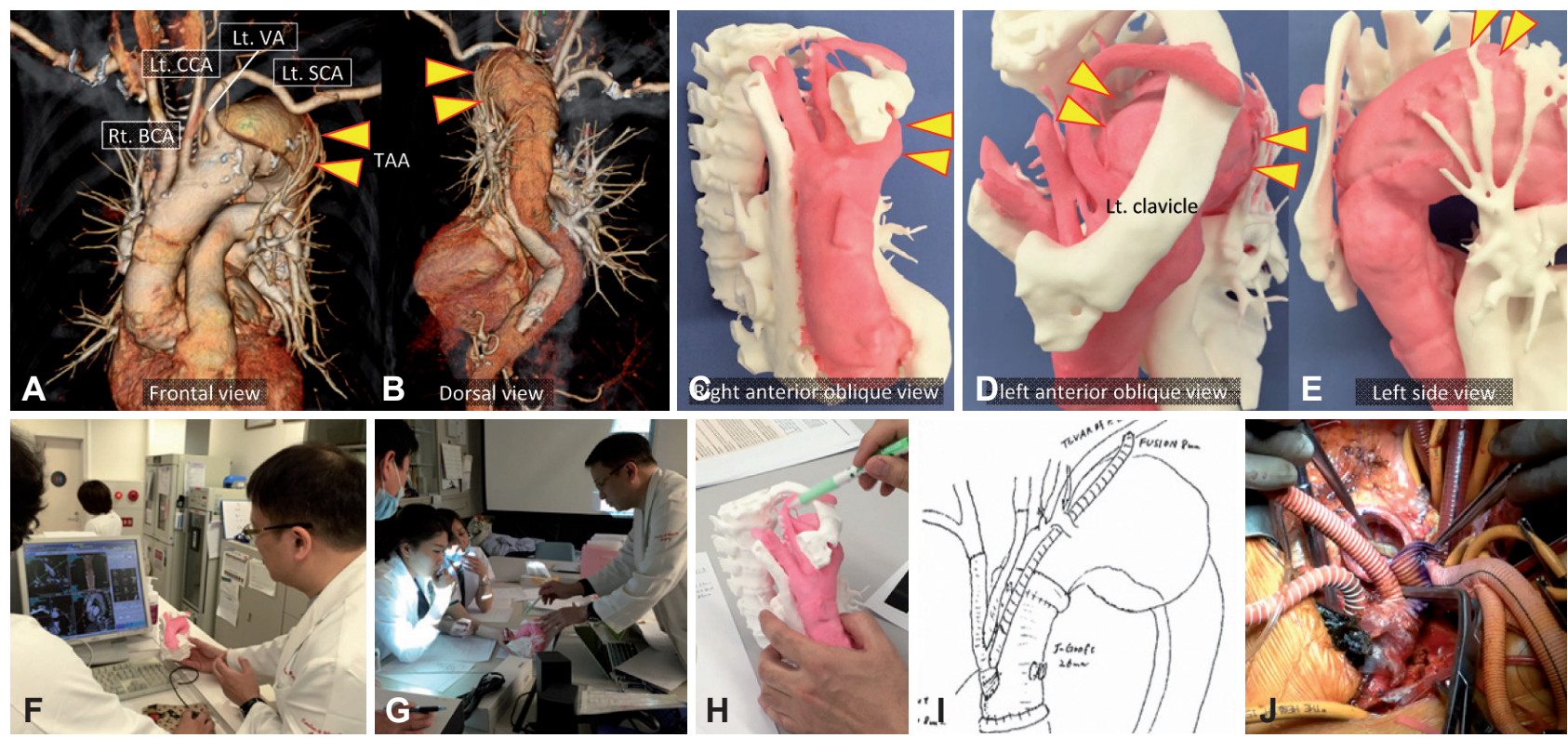

Fig. 12. A 69-year-old woman with residual aortic aneurysm after the replacement of the ascending thoracic aorta. CT volume rendering images (A and B) of an aortic aneurism show the residual dissection of the TAA (yellow arrows) distal to the Lt. SCA with an anomaly that originated from the Lt. VA. The three-dimensional printing model was able to replicate TAA (yellow arrows) and the complex anatomy of the surrounding structures in the half-size model (C-E) and could be used for validation with other modalities, procedural planning, and preoperative conference $(\mathrm{F}-\mathrm{I})$. She underwent hybrid thoracic endovascular aortic repair combined with supra-aortic debranching without complications (J). Adapted from Koyama and Suzuki, with permission of CHUGAIIGAKU Co., Ltd. [6]. TAA: thoracic aortic aneurysm, Lt. VA: left vertebral artery, Rt. BCA: right brachiocephalic artery, Lt. CCA: left common carotid artery, Lt. SCA: left subclavian artery. 
al planning and simulation for the verification of other modalities, informed consent, and preoperative conference (Figs. 11 and 12).

\section{Cardiac tumor}

Cardiac tumors are rare but may cause morbidity and mortality. Assessment of tissue characterization and tumor extent to regional and systemic hemodynamics is crucial [51,52]. In addition to conventional diagnostic imaging (US, CT, and MRI), $3 \mathrm{D}$ printed models can effectively integrate the diagnostic information in procedural planning and simulation [53-55].

\section{Education and training}

A recent study showed that the combined use of $3 \mathrm{D}$ printing models to conventional medical consultation was helpful to patients and their families for understanding the pathophysiology and therapy of diseases, such as complex CHDs and advanced heart failure compared with standard explanation alone [56]. In our experiences, quarter size $3 \mathrm{D}$ printed models of the heart that mimicked the morphological changes before and after cardiac resynchronization therapy (CRT) were effective for medical consultation to provide some supplemental information on the impact of CRT in patients (Fig. 13).

This is also applied to education for medical residents and professionals. Some studies have also shown that 3D printed models enhanced resident education and hands-on surgical training for young surgeons [57-59]. Before clinical practice, physical training and attempt are crucial for clinical success. Thus, more realistic training and simulation using $3 \mathrm{D}$ printed model are expected (Figs. 14 and 15). Although further studies are required
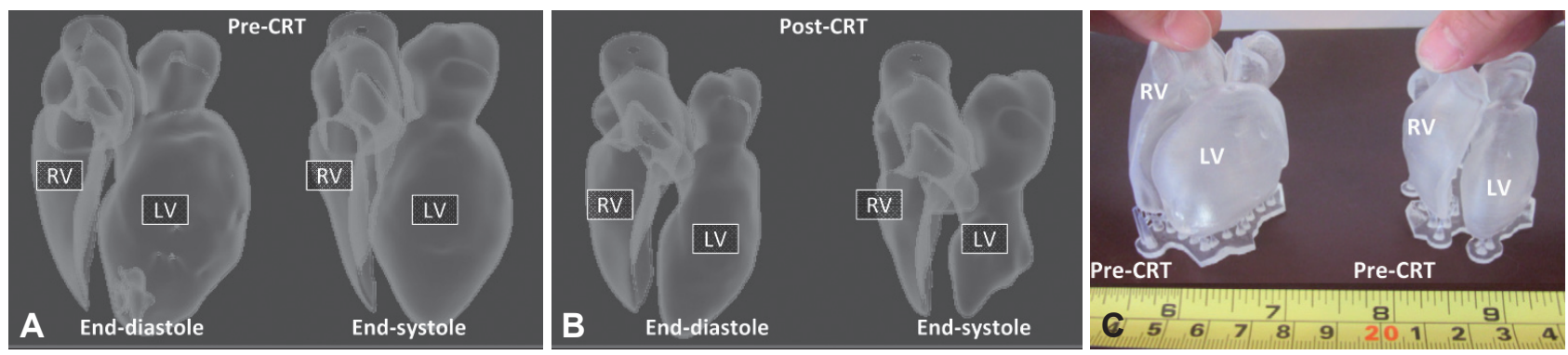

Fig. 13. A model of advanced heart failure. 3D printing models (A-C) imitate the actual quarter size of the RV and LV volumes in diastole and systole before and after CRT. 3D printing models have the potential to provide patients with some supplemental information on the impact of CRT to advanced heart failure. 3D: three-dimensional, RV: right ventricular, LV: left ventricular, CRT: cardiac resynchronisation therapy.
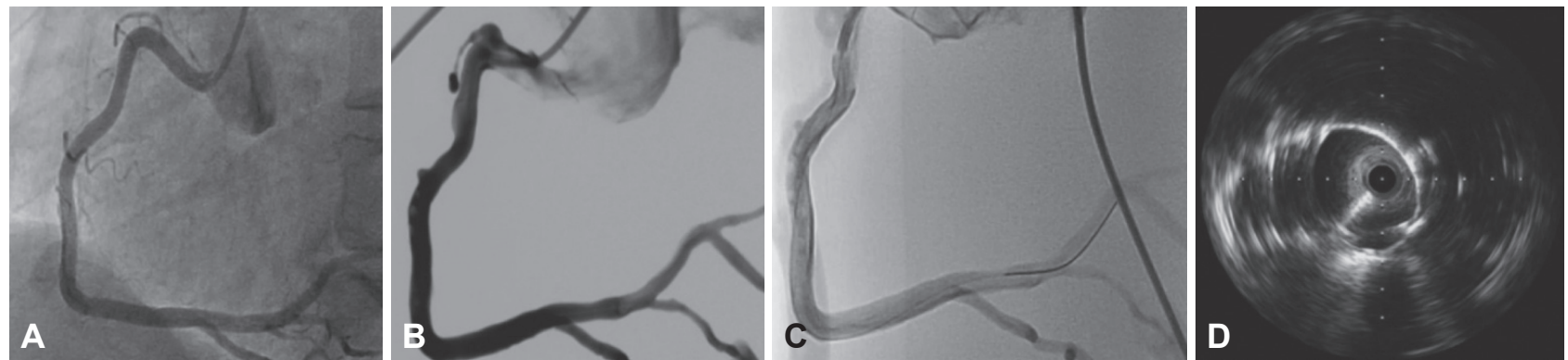

Fig. 14. Coronary angiography training model. Real invasive coronary angiography (A), physical training of coronary angiography using a solid three-dimensional (3D) printing model (B), coronary wire manipulation (C), and a cross-sectional image of intravascular ultrasound in the $3 \mathrm{D}$ printing coronary angiography model $(\mathrm{D})$.
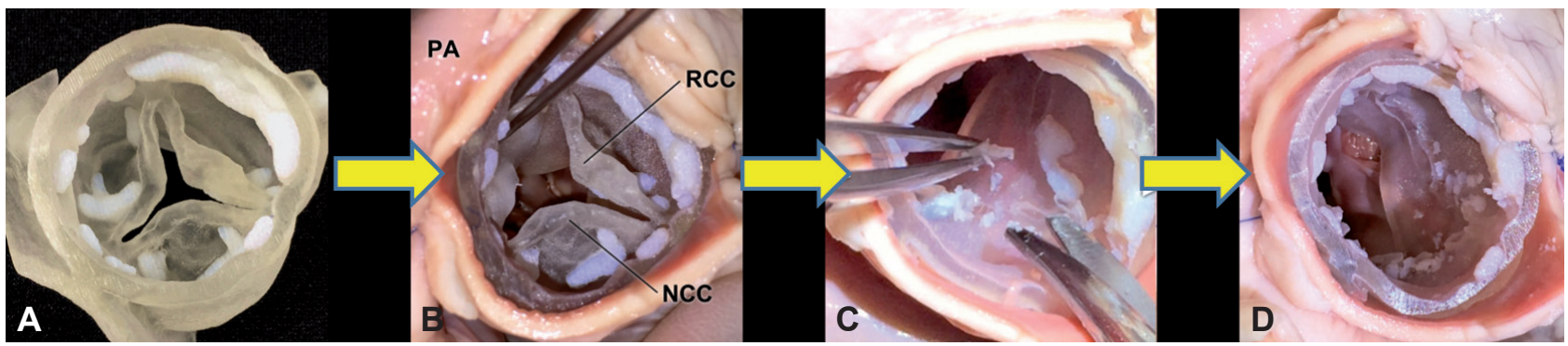

Fig. 15. Multiphysics model of aortic stenosis (AS). (A) A three-dimensional (3D) printed AS model with fragile and crushable calcifications for off-the-job. (B-D) Hybrid lab using the 3D model in a porcine heart for valve resection and decalcification. Because the texture of calcification is exquisitely adjusted for surgical training, it can be removed by forceps or ultrasonic aspirator. 
in the assessment of the true impact of 3D printed models [60], it has the potential to provide more standardized education, purpose-oriented training, and simulation as compared with traditional opportunity-based methods for a wide variety of cardiovascular diseases [61].

\section{FUTURE DIRECTIONS}

Because 3D printing models more accurately replicate the cardiovascular anatomy, the clinical applications have been focused on 'anatomy and function.' Kolli et al. [62] verified the impact of varying hemodynamic conditions on fractional flow reserve in an in vitro setting using 3D printing models. Maragiannis et al. [63] demonstrated that patient-specific models using fused dual-material could replicate both the anatomic and functional properties of severe degenerative aortic valve stenosis. Toninato et al. [64] investigated the hemodynamics of the sinus of Valsalva after bio-prosthetic aortic valve implantation in an in vitro study using $3 \mathrm{D}$ printing models. These approaches are promising to increase the clinical benefits of 3D printing models for clinical questions.

In addition, Biglino et al. [65] evaluated the distensibility of rubber-like materials to manufacture arterial phantoms using compliance tests. Yamada et al. [66] assessed the elastic modulus and breaking strength of the porcine heart, applied it to a biotexture, and evaluated the full surgery simulations using minimally invasive cardiac surgery tools, including a robot. Shirakawa et al. [67] made a 3D AS model with crushable calcifications for off-the-job training and surgical simulation (Fig. 15). These advanced attempts will achieve more realistic physical simulation and training.

Moreover, 3D bio-printing is one of the further advanced printing technologies when combined with cells, growth factors, and biomaterials to fabricate biomedical parts that maximally imitate natural tissue characteristics. Tissue engineering has recently been aligned with $3 \mathrm{D}$ printing technology to produce patient-specific organs. Fukunishi et al. [68] showed the mechanical properties and bio-compatibilities of patient-specific tissue-engineered vascular grafts in a sheep model by using bioprinting and $3 \mathrm{D}$ printing. While not discussed in this review, this advanced 3D bioprinting technology is promising for bringing fruitful outcomes to basic science and clinical research.

Some issues remain for the clinical uses of standard 3D printing models. Current clinical limitations are 1) initial and running costs (3D printer, material, and human resources), 2) time efficiency, and 3) the dependency on the operators' experiences and knowledge on 3D modelling and medicine. Although any issue will be resolved by each institutional decision, educational activities and promotion to medical reimbursement for cardiovascular 3D printing models may aid in the clinical applications.
With regard to the scientific value of using 3D printed models, we need to show both its clinical and scientific relevance. Byrne et al. [69] and Mathur et al. [70] recommend the scientific objectiveness as follows: 1) imaging modality for data acquisition; 2) segmentation and software requirements; 3 ) printer specifications; 4) material properties; 5) operating time (segmentation and production); and 6) need for organized multicenter trials. Recently, Valverde et al. [71] reported a multicenter trial on the effects of 3D models in surgical decision changes in patients with complex CHD. These specifications are necessary to improve the quality of publications and are helpful for clinical use.

\section{CONCLUSIONS}

Cardiovascular 3D printing models provide accurate 3D anatomy with physical spatial perception. With various and multiphysics materials, patient-tailored customized models hold great promise for clinical practice from disease diagnosis, planning, and simulation to education, training, and physiological evaluation, as well as further advanced translational researches. When cost-effectiveness and standardized workflow are established, 3D printing models will be an invaluable contribution to precision medicine.

\section{Conflicts of Interest}

The authors declare that they have no conflict of interest.

\section{Acknowledgments}

The authors appreciate the Japanese Society of Cardiovascular 3D-modeling in the medical 3D print (J3D) for their technical support. The authors want to thank Takafumi Masai (Sakurabashi Watanabe hospital), Kenji Fujii (Sakurabashi Watanabe hospital), Hiroshi Ito (Okayama University Graduate School of Medicine), Teruhito Mochizuki (Ehime University Graduate School of Medicine), and Masao Yoshitatsu (Kansai Rosai Hospital) for their invaluable review of this manuscript, and L \& L Co. Ltd., PHILIPS Healthcare, AZE Co Ltd., Siemens Healthcare, Photron M\&E Solutions Inc., and Bayer Yakuhin for their invaluable support.

\section{REFERENCES}

1. Mitsouras D, Liacouras P, Imanzadeh A, Giannopoulos AA, Cai T, Kumamaru KK, et al. Medical 3D printing for the radiologist. Radiographics 2015;35:1965-1988.

2. Giannopoulos AA, Mitsouras D, Yoo SJ, Liu PP, Chatzizisis YS, Rybicki FJ. Applications of 3D printing in cardiovascular diseases. Nat Rev Cardiol 2016;13:701-718.

3. Cantinotti M, Valverde I, Kutty S. Three-dimensional printed models in congenital heart disease. Int J Cardiovasc Imaging 2017;33:137-144.

4. Vukicevic M, Mosadegh B, Min JK, Little SH. Cardiac 3D printing and its future directions. JACC Cardiovasc Imaging 2017;10:171-184.

5. Valverde I. Three-dimensional printed cardiac models: applications in the field of medical education, cardiovascular surgery, and structural heart interventions. Rev Esp Cardiol (Engl Ed) 2017;70:282-291.

6. Koyama Y, Suzuki Y. Clinical cardiac CT: basic and practice. Tokyo: CHUGAIIGAKU Co., Ltd, 2016.

7. Yoo SJ, van Arsdell GS. 3D printing in surgical management of double outlet right ventricle. Front Pediatr 2018;5:289. 
8. Calleja A, Thavendiranathan P, Ionasec RI, Houle H, Liu S, Voigt I, et al. Automated quantitative 3-dimensional modeling of the aortic valve and root by 3 -dimensional transesophageal echocardiography in normals, aortic regurgitation, and aortic stenosis: comparison to computed tomography in normals and clinical implications. Circ Cardiovasc Imaging 2013;6:99108.

9. Witschey WR, Pouch AM, McGarvey JR, Ikeuchi K, Contijoch F, Levack $\mathrm{MM}$, et al. Three-dimensional ultrasound-derived physical mitral valve modeling. Ann Thorac Surg 2014;98:691-694.

10. Fukuyama N, Kurata A, Kawaguchi N, Tashiro R, Higaki T, Yokoi T, et al. Two-phase contrast injection protocol for pediatric cardiac computed tomography in children with congenital heart disease. Pediatr Cardiol 2018; 39:518-525.

11. Shirakawa T, Yoshitatsu M, Koyama Y, Kurata A, Miyoshi T, Mizoguchi H, et al. To what extent can 3D model replicate dimensions of individual mitral valve prolapse? J Artif Organs 2018;21:348-355.

12. Kim GB, Lee G, Kim H, Yang DH, Kim YH, Kyung YS, et al. Three-dimensional printing: basic principles and applications in medicine and radiology. Korean J Radiol 2016;17:182-197.

13. Mitsouras D, Liacouras PC. 3D printing technologies. In: Rybicki FJ, Grant GT, eds. 3D printing in medicine: a practical guide for medical professionals. Cham: Springer, 2017;5-22.

14. Maron BJ, Rowin EJ, Casey SA, Maron MS. How hypertrophic cardiomyopathy became a contemporary treatable genetic disease with low mortality: shaped by 50 years of clinical research and practice. JAMA Cardiol 2016;1:98-105.

15. Yang DH, Kang JW, Kim N, Song JK, Lee JW, Lim TH. Myocardial 3-dimensional printing for septal myectomy guidance in a patient with obstructive hypertrophic cardiomyopathy. Circulation 2015;132:300-301.

16. Maron BJ, Ferrans VJ, White RI Jr. Unusual evolution of acquired infundibular stenosis in patients with ventricular septal defect. Clinical and morphologic observations. Circulation 1973;48:1092-1103.

17. Shirakawa T, Koyama Y, Mizoguchi H, Yoshitatsu M. Morphological analysis and preoperative simulation of a double-chambered right ventricle using 3-dimensional printing technology. Interact Cardiovasc Thorac Surg 2016;22:688-690.

18. Nishimura RA, Otto CM, Bonow RO, Carabello BA, Erwin JP 3rd, Guyton RA, et al. 2014 AHA/ACC guideline for the management of patients with valvular heart disease: a report of the American College of Cardiology/American Heart Association Task Force on Practice Guidelines. J Am Coll Cardiol 2014;63:e57-185.

19. Nishimura RA, Otto CM, Bonow RO, Carabello BA, Erwin JP 3rd, Fleisher LA, et al. 2017 AHA/ACC focused update of the 2014 AHA/ACC guideline for the management of patients with valvular heart disease: a report of the American College of Cardiology/American Heart Association Task Force on Clinical Practice Guidelines. J Am Coll Cardiol 2017;70: 252-289.

20. Moat NE. Will TAVR become the predominant method for treating severe aortic stenosis? N Engl J Med 2016;374:1682-1683.

21. Figulla HR, Webb JG, Lauten A, Feldman T. The transcatheter valve technology pipeline for treatment of adult valvular heart disease. Eur Heart J 2016;37:2226-2239.

22. Fujita B, Kütting M, Seiffert M, Scholtz S, Egron S, Prashovikj E, et al. Calcium distribution patterns of the aortic valve as a risk factor for the need of permanent pacemaker implantation after transcatheter aortic valve implantation. Eur Heart J Cardiovasc Imaging 2016;17:1385-1393.

23. Ripley B, Kelil T, Cheezum MK, Goncalves A, Di Carli MF, Rybicki FJ, et al. 3D printing based on cardiac CT assists anatomic visualization prior to transcatheter aortic valve replacement. J Cardiovasc Comput Tomogr 2016;10:28-36

24. Gallo M, D’Onofrio A, Tarantini G, Nocerino E, Remondino F, Gerosa G. 3D-printing model for complex aortic transcatheter valve treatment. Int J Cardiol 2016;210:139-140.

25. Murphy DT, Blanke P, Alaamri S, Naoum C, Rubinshtein R, Pache G, et al. Dynamism of the aortic annulus: effect of diastolic versus systolic CT annular measurements on device selection in transcatheter aortic valve replacement (TAVR). J Cardiovasc Comput Tomogr 2016;10:37-43.

26. Fujita B, Kütting M, Scholtz S, Utzenrath M, Hakim-Meibodi K, Paluszkiewicz L, et al. Development of an algorithm to plan and simulate a new interventional procedure. Interact Cardiovasc Thorac Surg 2015;21:87-95.

27. Mahmood F, Owais K, Montealegre-Gallegos M, Matyal R, Panzica P, Maslow A, et al. Echocardiography derived three-dimensional printing of normal and abnormal mitral annuli. Ann Card Anaesth 2014;17:279-283.

28. Little SH, Vukicevic M, Avenatti E, Ramchandani M, Barker CM. 3D printed modeling for patient-specific mitral valve intervention: repair with a clip and a plug. JACC Cardiovasc Interv 2016;9:973-975.

29. Dankowski R, Baszko A, Sutherland M, Firek L, Kałmucki P, Wróblewska $\mathrm{K}$, et al. $3 \mathrm{D}$ heart model printing for preparation of percutaneous structural interventions: description of the technology and case report. Kardiol Pol 2014;72:546-551.

30. Castriota F, Nerla R, Squeri A, Micari A, Del Giglio M, Cremonesi A. Needing a helping hand: left Amplatz catheter to facilitate anterior leaflet grasping in the MitraClip procedure. JACC Cardiovasc Interv 2016;9:e91e93.

31. Poterucha JT, Foley TA, Taggart NW. Percutaneous pulmonary valve implantation in a native outflow tract: 3-dimensional DynaCT rotational angiographic reconstruction and 3-dimensional printed model. JACC Cardiovasc Interv 2014;7:e151-e152.

32. Olivieri LJ, Krieger A, Loke YH, Nath DS, Kim PC, Sable CA. Three-dimensional printing of intracardiac defects from three-dimensional echocardiographic images: feasibility and relative accuracy. J Am Soc Echocardiogr 2015;28:392-397.

33. Shiraishi I, Kajiyama Y, Yamagishi M, Hamaoka K. Images in cardiovascular medicine. Stereolithographic biomodeling of congenital heart disease by multislice computed tomography imaging. Circulation 2006;113:e733e734.

34. Shiraishi I, Yamagishi M, Hamaoka K, Fukuzawa M, Yagihara T. Simulative operation on congenital heart disease using rubber-like urethane stereolithographic biomodels based on 3D datasets of multislice computed tomography. Eur J Cardiothorac Surg 2010;37:302-306.

35. Kurata A, Higaki T, Kojima A, Uchita S, Koyama Y, Miyoshi T, et al. 3-D simulation of pulmonary artery surgery in children with congenital heart disease using CT/CT image fusion and 3-D rapid printing: description of the technology and case report. Abstracts of the 11th Annual Scientific Meeting of the Society of Cardiovascular Computed Tomography. J Cardiovasc Comput Tomogr 2016;10:s7.

36. Kiraly L, Tofeig M, Jha NK, Talo H. Three-dimensional printed prototypes refine the anatomy of post-modified Norwood-1 complex aortic arch obstruction and allow presurgical simulation of the repair. Interact Cardiovasc Thorac Surg 2016;22:238-240.

37. Mottl-Link S, Hübler M, Kühne T, Rietdorf U, Krueger JJ, Schnackenburg $\mathrm{B}$, et al. Physical models aiding in complex congenital heart surgery. Ann Thorac Surg 2008;86:273-277.

38. van der Linde D, Konings EE, Slager MA, Witsenburg M, Helbing WA, Takkenberg JJ, et al. Birth prevalence of congenital heart disease worldwide: a systematic review and meta-analysis. J Am Coll Cardiol 2011;58: 2241-2247.

39. Sodian R, Weber S, Markert M, Loeff M, Lueth T, Weis FC, et al. Pediatric cardiac transplantation: three-dimensional printing of anatomic models for surgical planning of heart transplantation in patients with univentricular heart. J Thorac Cardiovasc Surg 2008;136:1098-1099.

40. Noecker AM, Chen JF, Zhou Q, White RD, Kopcak MW, Arruda MJ, et al. Development of patient-specific three-dimensional pediatric cardiac models. ASAIO J 2006;52:349-353.

41. Sodian R, Schmauss D, Schmitz C, Bigdeli A, Haeberle S, Schmoeckel M, et al. 3-dimensional printing of models to create custom-made devices for coil embolization of an anastomotic leak after aortic arch replacement. Ann Thorac Surg 2009;88:974-978.

42. O'Neill B, Wang DD, Pantelic M, Song T, Guerrero M, Greenbaum A, et al. Transcatheter caval valve implantation using multimodality imaging: 
roles of TEE, CT, and 3D printing. JACC Cardiovasc Imaging 2015;8:221225.

43. Kim MS, Hansgen AR, Wink O, Quaife RA, Carroll JD. Rapid prototyping: a new tool in understanding and treating structural heart disease. Circulation 2008;117:2388-2394.

44. Kent WD, Appoo JJ, Bavaria JE, Herget EJ, Moeller P, Pochettino A, et al. Results of type II hybrid arch repair with zone 0 stent graft deployment for complex aortic arch pathology. J Thorac Cardiovasc Surg 2014;148:29512955.

45. Moulakakis KG, Mylonas SN, Markatis F, Kotsis T, Kakisis J, Liapis CD. A systematic review and meta-analysis of hybrid aortic arch replacement. Ann Cardiothorac Surg 2013;2:247-260.

46. Iba Y, Minatoya K, Matsuda H, Sasaki H, Tanaka H, Oda T, et al. How should aortic arch aneurysms be treated in the endovascular aortic repair era? A risk-adjusted comparison between open and hybrid arch repair using propensity score-matching analysis. Eur J Cardiothorac Surg 2014;46: 32-39.

47. Faulds J, Sandhu HK, Estrera AL, Safi HJ. Minimally invasive techniques for total aortic arch reconstruction. Methodist Debakey Cardiovasc J 2016;12:41-44.

48. Schmauss D, Juchem G, Weber S, Gerber N, Hagl C, Sodian R. Three-dimensional printing for perioperative planning of complex aortic arch surgery. Ann Thorac Surg 2014;97:2160-2163.

49. Valverde I, Gomez G, Coserria JF, Suarez-Mejias C, Uribe S, Sotelo J, et al. $3 \mathrm{D}$ printed models for planning endovascular stenting in transverse aortic arch hypoplasia. Catheter Cardiovasc Interv 2015;85:1006-1012.

50. Shijo T, Shirakawa T, Yoshitatsu M, Iwata K. Stent grafting simulation using a three-dimensional printed model for extensive aortic arch repair combined with coarctation. Eur J Cardiothorac Surg 2018;54:593-595.

51. Araoz PA, Eklund HE, Welch TJ, Breen JF. CT and MR imaging of primary cardiac malignancies. Radiographics 1999;19:1421-1434.

52. Araoz PA, Mulvagh SL, Tazelaar HD, Julsrud PR, Breen JF. CT and MR imaging of benign primary cardiac neoplasms with echocardiographic correlation. Radiographics 2000;20:1303-1319.

53. Schmauss D, Gerber N, Sodian R. Three-dimensional printing of models for surgical planning in patients with primary cardiac tumors. J Thorac Cardiovasc Surg 2013;145:1407-1408.

54. Son KH, Kim KW, Ahn CB, Choi CH, Park KY, Park CH, et al. Surgical planning by $3 \mathrm{D}$ printing for primary cardiac schwannoma Resection. Yonsei Med J 2015;56:1735-1737.

55. Jacobs S, Grunert R, Mohr FW, Falk V. 3D-Imaging of cardiac structures using 3D heart models for planning in heart surgery: a preliminary study. Interact Cardiovasc Thorac Surg 2008;7:6-9.

56. Biglino G, Koniordou D, Gasparini M, Capelli C, Leaver LK, Khambadkone $\mathrm{S}$, et al. Piloting the use of patient-specific cardiac models as a novel tool to facilitate communication during cinical consultations. Pediatr Cardiol 2017;38:813-818.

57. Loke YH, Harahsheh AS, Krieger A, Olivieri LJ. Usage of 3D models of tetralogy of Fallot for medical education: impact on learning congenital heart disease. BMC Med Educ 2017;17:54.
58. Costello JP, Olivieri LJ, Su L, Krieger A, Alfares F, Thabit O, et al. Incorporating three-dimensional printing into a simulation-based congenital heart disease and critical care training curriculum for resident physicians. Congenit Heart Dis 2015;10:185-190.

59. Hermsen JL, Burke TM, Seslar SP, Owens DS, Ripley BA, Mokadam NA, et al. Scan, plan, print, practice, perform: development and use of a patientspecific 3-dimensional printed model in adult cardiac surgery. J Thorac Cardiovasc Surg 2017;153:132-140.

60. Wang Z, Liu Y, Luo H, Gao C, Zhang J, Dai Y. Is a three-dimensional printing model better than a traditional cardiac model for medical education? A pilot randomized controlled study. Acta Cardiol Sin 2017;33:664669.

61. Yoo SJ, Spray T, Austin EH 3rd, Yun TJ, van Arsdell GS. Hands-on surgical training of congenital heart surgery using 3-dimensional print models. J Thorac Cardiovasc Surg 2017;153:1530-1540.

62. Kolli KK, Min JK, Ha S, Soohoo H, Xiong G. Effect of varying hemodynamic and vascular conditions on fractional flow reserve: an in vitro study. J Am Heart Assoc 2016;5:e003634.

63. Maragiannis D, Jackson MS, Igo SR, Schutt RC, Connell P, Grande-Allen $\mathrm{J}$, et al. Replicating patient-specific severe aortic valve stenosis with functional 3D modeling. Circ Cardiovasc Imaging 2015;8:e003626.

64. Toninato R, Salmon J, Susin FM, Ducci A, Burriesci G. Physiological vortices in the sinuses of Valsalva: an in vitro approach for bio-prosthetic valves. J Biomech 2016;49:2635-2643.

65. Biglino G, Verschueren P, Zegels R, Taylor AM, Schievano S. Rapid prototyping compliant arterial phantoms for in-vitro studies and device testing. J Cardiovasc Magn Reson 2013;15:2.

66. Yamada T, Osako M, Uchimuro T, Yoon R, Morikawa T, Sugimoto M, et al. Three-dimensional printing of life-like models for simulation and training of minimally invasive cardiac surgery. Innovations (Phila) 2017;12:459465.

67. Shirakawa T, Yoshitatsu M, Koyama Y, Mizoguchi H, Toda K, Sawa Y. 3Dprinted aortic stenosis model with fragile and crushable calcifications for off-the-job training and surgical simulation. Multimed Man Cardiothorac Surg 2018 May 14 [Epub].http://doi.org/10.1510/mmcts.2018.018.

68. Fukunishi T, Best CA, Sugiura T, Opfermann J, Ong CS, Shinoka T, et al. Preclinical study of patient-specific cell-free nanofiber tissue-engineered vascular grafts using 3-dimensional printing in a sheep model. J Thorac Cardiovasc Surg 2017;153:924-932.

69. Byrne N, Velasco Forte M, Tandon A, Valverde I, Hussain T. A systematic review of image segmentation methodology, used in the additive manufacture of patient-specific 3D printed models of the cardiovascular system. JRSM Cardiovasc Dis 2016;5:2048004016645467.

70. Mathur M, Patil P, Bove A. The role of 3D printing in structural heart disease: all that glitters is not gold. JACC Cardiovasc Imaging 2015;8:987-988.

71. Valverde I, Gomez-Ciriza G, Hussain T, Suarez-Mejias C, Velasco-Forte MN, Byrne N, et al. Three-dimensional printed models for surgical planning of complex congenital heart defects: an international multicentre study. Eur J Cardiothorac Surg 2017;52:1139-1148. 